study, the role that non-IVDU prostitutes play in perpetuating the AIDS pandemic in Spain seems still to be low.

We believe that data presented here support the hypothesis that the risk of sexual transmission of HCV is low, although additional studies are needed to define more precisely this risk. The study also indicates that, at present in our country, it is the intravenous drug user who puts prostitutes at a significant risk of $\mathrm{HCV}$ infection and this also seems to be the case for HIV infection among the same group.

S ECHEVARRIA
G SAN MIGUEL
T PELAYO*
C SALAS
F CASAFONT
J CRESPO
PONS ROMERO
astroenterology Unit.
University Hospital.
Medicine, Santander.
mbiente de Cantabria.

Address correspondence to: Santiago Echevarria, Urbanización Los Jardines 25, 39600 Muriedas, Santander, Spain.

1 Alter MJ. Inapparent transmission of hepatitis C Footprints in the sand. Hepatology 1991;14:389-91.

2 Alter HJ. Descartes before the horse: I clone, therefore I am: the hepatitis C virus in current perspective. Ann am: the hepatitis $C$ virus in

3 Esteban JI, Esteban R, Viladomiu L, et al. Hepatitis C virus antibodies among risk groups in Spain. Lancet 1989;2:294-97.

4 Perez-Romero M, Sanchez-Quijano A, Lissen E. Transmission of hepatitis C virus. Ann Intern Med 1990;113:411-2 (correspondence).

5 Evenhart JE, Di Bisciglie AM, Murray LM, et al. Risk for non-A non-B (type $C$ ) hepatitis through sexual or non-A non-B (type C) hepatitis through sexual or Med 1990;112:544-5.

6 Padian NJ. Prostitute women and AIDS: epidemiology. AIDS 1988:2:413-9.

Accepted for publication 2 March 1993.

\section{Transmission of gonorrhoea through an inflatable doll}

Nonsexual transmission of gonorrhoea seems to be extremely rare. Only one case of nonsexual transmission of genital Neisseria gonorrhoeae is documented in adults ${ }^{1}$, involving two patients in a military hospital who shared a urinal. $\mathbf{N}$ gonorrhoeae has been shown to survive in infected secretions on towels and handkerchiefs for 20 and 24 hours, respectively. ${ }^{2}$ Cultures from toilet seats in public restrooms and venereal disease clinics have failed to yield $\mathbf{N}$ gonorrhoeae. ${ }^{34}$

The skipper from a trawler, who had been 3 months at sea, sought advice for urethral discharge. His symptoms had lasted for two weeks. A urethral smear showed typical intracellular gram-negative diplococci, and a culture was positive for $\mathrm{N}$ gonorrhoeae. There had been no woman onboard the trawler; he denied homosexual contacts; and there was no doubt that the onset of the symptoms was more than two months after leaving the port.

With some hesitation, he told the story. A few days before onset of his symptoms, he had roused the engineer in his cabin during the night because of engine trouble. After the engineer had left his cabin, the skipper found an inflatable doll with artificial vagina in his bed, and he was tempted to have "intercourse" with the doll. His complaints started a few days after this episode.

The engineer was examined, and was found to have gonorrhoea. He had observed a mild urethral discharge since they left port, but he had not been treated with antibiotics. $\mathrm{He}$ admitted to having ejaculated into the "vagina" of the doll just before the skipper called him, without washing the doll afterwards. He also admitted intercourse with a girl in another town some days before going to sea. This girl was traced, but the result of her examination is not known. To the best of our knowledge, no case of gonococcal transmission through an inflatable doll has been reported before.

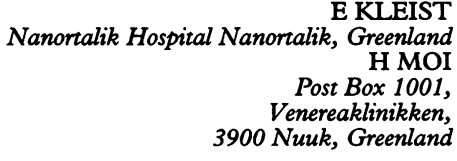

1 Neinstein LS, Goldenring J, Carpenter S. Nonsexual ransmission of sexually transmitted diseases: an infrequent occurrence. Pediatrics 1984;74:67-76.

2 Srivastava AC. Survival of gonococci in urethral secretions with reference to the nonsexual transmission of gonococcal infection. $₹$ Med Microbiol 1980;13:593-6.

3 Gilbaugh $J \mathrm{H}$, Fuchs PC. The gonococcus and the toilet seat. $N$ Engl f Med 1979;301:91-3.

4 Rein MF. Nonsexual acquisition of gonococcal infection (letter). N Engl ₹ Med 1979;301:1347.

Analysis of failed appointments in a genitourinary department in the West Midlands of the UK

Failure to keep hospital out-patient appointments is a waste of resources and it may contribute to increased morbidity. ${ }^{1}$ Previous studies focused attention on defaulters of initial outpatient appointments. ${ }^{23} \mathrm{We}$ report on the failure to keep subsequent appointments in a genitourinary department.

Between the period 11 May-10 July 1992, all patients who failed to keep their subsequent appointments were studied and analysed. Whenever they returned to the clinic, they were interviewed with particular attention to their reasons for missing their previous appointments. The interview of those who returned was continued until the end of August 1992. A large proportion of our patients are in the lower socio-economic classes. Statistical analysis was by the $\mathrm{Chi}$ square method and Student's $t$ test, with $\mathrm{p}<0.05$ taken as significant.

During the period of study, 2973 appointments were scheduled for 76 clinic sessions. There were 745 failed appointments giving a frequency rate of $25 \cdot 1 \%$. Among the appointments, 1654 were for morning sessions and 1319 for afternoon sessions, of which 454 and 291 respectively were not kept, $27 \cdot 4 \% \mathrm{v}$. $22.1 \%$, p $<0.001$. There were 1479 male and 1494 female appointments, out of which 